\title{
WORK AND PLAY: INTERNATIONAL EVIDENCE OF GENDER EQUALITY IN EMPLOYMENT AND SPORTS
}

\author{
Michael W. Klein \\ Working Paper 9081 \\ http://www.nber.org/papers/w9081 \\ NATIONAL BUREAU OF ECONOMIC RESEARCH \\ 1050 Massachusetts Avenue \\ Cambridge, MA 02138 \\ July 2002
}

I thank Andrew Bernard, Todd Idson and Matt Kahn for helpful comments. The views expressed herein are those of the author and not necessarily those of the National Bureau of Economic Research.

(C) 2002 by Michael W. Klein. All rights reserved. Short sections of text, not to exceed two paragraphs, may be quoted without explicit permission provided that full credit, including (C) notice, is given to the source. 
Work and Play: International Evidence of Gender Equality in Employment and Sports Michael W. Klein

NBER Working Paper No. 9081

July 2002

JEL No. J16, L83

\begin{abstract}
This paper addresses the question of whether societies that afford economic opportunity to women offer other opportunities as well. The analysis in this paper shows that the performance of a country's women in international athletic competition reflects the degree of their relative participation in that country's labor market. There is a significant positive relationship across countries between a high ratio of the labor force participation rate of women to the labor force participation rate of men and the number and type of medals won by a country's women in the 2000 Sydney Summer Olympics. Teams representing countries with high relative labor force participation rates also were both more likely to qualify for the 1999 Women's Soccer World Cup and to do well in that competition. This effect of relative labor force participation rates on athletic success is found while controlling for a nation's income per capita, population, men's performance in related sporting events, rate of participation of women in government, and fertility rate. These results suggest that the participation of women in a country's labor force is an important reflection of their opportunities in other areas as well.
\end{abstract}

Michael W. Klein

Fletcher School of Law and Diplomacy

Tufts University

Medford, MA 02155

and NBER

michael.klein@tufts.edu

617-627-2718 


\section{Introduction}

What can a country's performances in international sporting events, like the Olympics or the World Cup, teach us about its society? World-class level competitors are more likely to come from more populous countries, all else equal, since these nations represent larger pools of potential talent. The percentage of a country's population that has the opportunity to develop their athletic talent is larger in richer countries where people are healthier, the young are less likely to be engaged in work, and more resources are devoted to leisure activities, including sports. A number of studies have shown that, in fact, population and per capita income are significant determinants of Olympic success. $^{1}$

The analysis in this paper demonstrates that another key characteristic of a country, one not studied in any previous research on this topic, is related to the achievements of its citizens in international athletic competitions. The performance of a country's women in international sporting events is related to the economic opportunities afforded them, as measured by the ratio of the labor force participation rate of women to the labor force participation rate of men. This result is consistently obtained in regressions in which we control for population and per capita income, as well as the athletic success of a country's men, a variable that can capture a range of unobservable factors that reflect a country's commitment to sports. We also provide evidence that the explanatory power of the ratio of labor force participation rates on women's athletic

\footnotetext{
${ }^{1}$ Studies of the determinants of the success of a country's athletes at the Summer Olympics include the analyses of the 1964 games by Donald W. Ball (1972), the 1972 games by Ned Levine (1974) and by A. Ray Grimes, William J. Kelly and Paul H. Rubin (1974), a panel of 24 Summer Olympiads over the period 1896 to 2000 by Gerard Kuper and Elmer Sterken (2001a), the post-World War II Summer Olympic Games by Daniel K.N. Johnson and Ayfer Ali (2000, 2002), and the Summer Olympic Games from 1960 to 1996 by Andrew B. Bernard and Meghan R. Busse (2000).
} 
success is not merely reflecting the effect of the role of women in a country's government or its fertility rate, even though these two variables are both correlated with the ratio of labor force participation rates and each explains, to some extent, the success of women in international athletic competitions. These results suggest that the cross-country evidence of the participation of women in a country's labor force is an important reflection of their opportunities in other areas of society as well.

These results are based on evidence from the Sydney Summer Olympics in 2000 and Women's Soccer World Cup in $1999 .^{2}$ We conduct a variety of tests, including ones on the number and type of Olympic medals earned, the likelihood of qualifying for the World Cup, and the number of points earned in World Cup Competition. These competitions are well suited for our analysis since they include a much wider pool of countries than other international sporting events, like Wimbledon or the Winter Olympics, where competitors are typically drawn from a narrow set of industrial countries.

The relationship between the ratio of labor force participation rates and number of Olympic medals won can be sizeable. For example, our estimates suggest that women from a country at the $75^{\text {th }}$ percentile of this variable won almost 3 more medals than their sisters who hail from a country at the $25^{\text {th }}$ percentile. To illustrate this, we note that Canadian women won 7 medals in Sydney while Spanish women won 4. The main difference between these countries is not income, or population, but the fact that Canada

\footnotetext{
${ }^{2}$ There are no other studies, to my knowledge, of the economic and demographic determinants of the success of countries in either the Women's or Men's Soccer World Cup competition comparable to the ones on the determinants of success in Olympic competition.
} 
is at the $75^{\text {th }}$ percentile of the ratio of labor force participation rates of women relative to men while Spain is at the $25^{\text {th }}$ percentile.

In the next section of this paper we describe both our main measure of women's relative integration in the labor force, the ratio of labor force participation rates, and our cross-country indicators of women's international athletic performance. We also provide some statistics on both of these variables and their relationship in this section. We then present a more complete analysis of the relationship between the performance of a country's women in the 2000 Sydney Summer Olympics and its ratio of labor force participation rates. This is followed by a similar analysis using data from the 1999 Women's World Cup. Section V offers some concluding comments.

\section{Labor Force Participation and Athletic Performance: A First Look}

The central idea of this paper is that cross-country evidence of women's performance in international athletic competition reflects differences across countries in women's economic opportunities, as manifested by their relative rates of participation in a nation's labor market. ${ }^{3}$ In this section, we describe the main sets of variables used to test this hypothesis. Some initial statistics on the relationship between women's presence in the labor market and their performance in international athletic competition, presented at the end of this section, serve as a warm-up for the regression analysis that follows in the next two sections.

\footnotetext{
${ }^{3}$ It would be desirable to use in this analysis, in addition to the ratio of labor force participation rates, a variable that reflects the ratio of women's wages to men's wages, controlling for differences in human capital across the sexes, but there is no series like this available for a wide cross-section of countries.
} 


\section{II.A. Labor Market Participation}

In a survey article on women's labor force participation and economic development, Kristin Mammen and Christina Paxson (2000) write "Women's labor force status relative to that of men is an important benchmark of their status in society." (p. 141). The World Bank Development Indicators 2001 volume echoes this idea with the text accompanying the table presenting the ratio of labor force participation rates of women relative to that of men, which reads "Girls in many developing countries are allowed less education than boys are - a disparity reflected in lower female primary enrollment and higher female illiteracy. As a result, women have fewer employment opportunities, especially in the formal sector." (p. 23).

In this paper, we use the 1999 value of the ratio of labor force participation rates (which we call LaborRatio) as an indicator of women's economic opportunities in a country in that year. This ratio represents the rate of economically active women relative to the rate of economically active men. ${ }^{4}$ The distribution of this variable is depicted in the histogram in Figure 1. This histogram reflects the fact that 73 countries, representing almost half the sample, had a value of LaborRatio less than 0.72 . Another 45 percent of the sample, representing 68 countries, had a value of LaborRatio between 0.72 and 0.91 , and the remaining 8 countries, with a value of LaborRatio greater than 0.91 , were all countries with levels of income per capita of less than $\$ 800$ in 1999 . We note that the World Development Indicators 2001 includes the remark that a value of unity of

\footnotetext{
${ }^{4}$ The International Labor Organization defines the economically active population as all those who supply labor for the production of goods and services during a specified period, including both the employed and the unemployed.
} 
LaborRatio indicates gender equality. But only 2 of the 149 countries in this sample, Cambodia and Ghana, have values of LaborRatio equal to or greater than $1 .{ }^{5}$

While the eight countries with the highest values of the ratio of labor force participation rates all had low levels of income per capita, the 26 countries in the sample with a value of LaborRatio below 0.52 (the value for Ireland) all had levels of income per capita below $\$ 8,100$, and 22 of these countries had a level of income per capita below $\$ 4,000$. Mammen and Paxson (2000) show that, across countries, there is a U-shaped relationship between the rate of women participating in the labor force and the logarithm of income per capita. As shown in Figure 2, a similar relationship holds for LaborRatio and the logarithm of income per capita in our sample of 149 countries. The solid line in this figure represents the estimated relationship between LaborRatio and two regressors, the logarithm of income per capita and the squared value of the logarithm of income per capita. The estimated regression result is

$$
\text { LaborRatio }=2.11-0.36 \ln \text { GDPcap }+0.02 \ln G D P \text { cap }^{2}
$$

where $\ln G D P c a p$ is the natural logarithm of income per capita. The coefficients on both income and income squared are significant at better than the 99 percent level of confidence and the $\mathrm{R}^{2}$ of this regression is 0.13 .

The minimum point of the quadratic function corresponds to a level of income per capita of about $\$ 3700$, which is close to the levels of income per capita for Mexico and Botswana. At this level of income, the estimated value of LaborRatio is 0.63 . In fact, the lowest values of LaborRatio among the countries in our data set are well below this, with

\footnotetext{
${ }^{5}$ The correlations between LaborRatio, which is calculated using 1999 values of the labor force participation rates, and the same ratios calculated with data for 1994, 1989, and 1979 are $0.998,0.995$ and 0.945 , respectively, for the 149 countries used in the analysis of the Olympics. The results reported in the
} 
0.23 for Saudi Arabia, 0.32 for Belize, and 0.33 for Jordan. The three countries with the highest values of LaborRatio in our data set are Tanzania (0.95), Cambodia (1.00) and

Ghana (1.01), all of which had annual income per capita in 1999 of less than $\$ 500$.

Consistent with the U-shaped fitted relationship between LaborRatio and the logarithm of income per capita, richer countries are also counted among those with the highest levels of the ratio of labor force participation rates. For example, seven rich countries had a value of LaborRatio greater than 0.80, including the United States (0.82), Canada (0.82), Iceland (0.84), Denmark (0.85), Norway (0.85), Finland (0.88) and Sweden (0.90).

\section{$\underline{\text { II.B Performance in International Athletic Events }}$}

One criterion in the choice of indicators used in this paper to measure national athletic performance is to select variables that allow for the widest possible set of countries in our data set. Therefore, we use the results of the Summer Olympics and the Women's World Cup. We use two variables reflecting the outcomes of the 2000 Sydney Olympics and two variables indicating performance in the 1999 Women's World Cup. The two Olympic variables are Medals, which is the number of Olympic medals won by women, and MedalPoints, a point-weighted measure of the number of Olympic medals won by women, where a gold medal counts as 5 points, a silver medal as 3 points, and a bronze medal as 1 point. $^{6}$ The two measures reflecting the outcome of the 1999

rest of this paper are virtually identical to those obtained by replacing LaborRatio with an average of the labor force participation rates in 1979, 1989 and 1999.

${ }^{6}$ Grimes, Kelley and Rubin (1974), Levine (1974), and Bernard and Busse (2000) do not distinguish across types of medals while Ball (1972) used weights of 3, 2 and 1 for gold, silver and bronze, Johnson and Ali (2000) used an ordered probit model and Kuper and Sterken (2001a) ran separate regressions for each type of medal. While counting medals in most cases is straightforward, some clarification is worth noting. A team medal counts as one medal for a country. A medal in mixed doubles badminton counts as a medal for a woman (there is no mixed doubles in Olympic tennis). In several events (especially Judo) there were ties 
Women's World Cup competition are Cup99, a dummy variable that takes the value of 1 if a country qualified for the 1999 Women's World Cup and otherwise equals 0, and Cup99Points, a variable that adds to the values of Cup99, for the sixteen countries that qualified for the Women's World Cup, the number of points earned in competition, where a win is worth 3 points, a draw is worth 1 point and a loss is worth 0 points.

Some initial statistics showing the relationship between LaborRatio and each of the four measures of international athletic performance are presented in Table 1. Each row of this table represents the sum of the values of Medals, MedalPoints, Cup99, and Cup99Points for the set of countries in one of the quartiles of LaborRatio. Note that the values of LaborRatio that define the quartiles differ somewhat between the 149 countries that competed in the Sydney Summer Olympics for which we have complete data and the 54 countries that were involved in the 1999 Women's World Cup competition for which we have complete data. ${ }^{7}$

Medals were awarded to women from 59 different countries at the 2000 Summer Olympics in Sydney. We have data on labor force participation rates, and other regressors used in our subsequent analysis, for 55 of these countries, as well as for 94 other countries whose women participated in Sydney but did not win any medals. ${ }^{8}$ Table 1 shows that the countries that had values of LaborRatio in the lowest quartile (that is,

and each medal was counted - for example, two bronze medals were awarded in Women's Extra Lightweight Class in Judo, one to a Belgian woman and one to a German woman, and this was recorded as a bronze medal for each country.

${ }^{7}$ The 54 countries used in the analysis of the World Cup represent 53 countries that attempted to qualify for World Cup plus the United States that, by virtue of being the host country, was automatically awarded one of the 16 qualifying slots. As discussed below, 6 other countries that competed in the World Cup qualifying rounds (but not the World Cup itself) could not be included in our analysis because of missing data.

${ }^{8}$ The four countries whose women won medals but for which we do not have complete data are Cuba, North Korea, Taiwan, and Yugoslavia. 
between 0.22 and 0.56 ) won about one-seventh the number of medals of the countries in the next highest quartile (which had values of LaborRatio between 0.56 and 0.73 ), about one-tenth the number of medals won by countries in the third quartile (which had values of LaborRatio between 0.73 and 0.84 ), and about one-eighth the number of medals won by countries in the highest quartile (which had values of LaborRatio between 0.84 and 1.01). The disparity across quartiles in the sum of the values of MedalPoints is even more pronounced, especially when comparing the lowest quartile to the two highest quartiles. One reflection of this is that women from countries in the lowest quartile won 20 gold medals while women from countries in the third quartile won 47 gold medals and women from countries in the highest quartile won 42 gold medals.

The relative shortfall in performance among countries in the lowest quartile of LaborRatio is also apparent in the two variables related to the 1999 Women's World Cup. Only two countries in the lowest quartile of this set of 54 countries (Brazil, the country at the $25^{\text {th }}$ percentile in terms of the value of LaborRatio, and Mexico), and two countries in the second quartile (Nigeria and Italy) qualified for the competition in 1999, with the other twelve teams that qualified coming from countries with values of LaborRatio above the median value of 0.67 . Teams from countries in the highest quartile earned, collectively, the most points. This reflects the fact that more teams came from this quartile than any of the lower ones as well as the fact that the average number of points earned by a team from this quartile was larger than the average number of points earned by a team from any of the lower quartiles.

The U-shaped relationship between LaborRatio and income per capita suggests that the set of countries in the quartile with the highest values of LaborRatio are drawn 
from both the richest and the poorest countries in the sample. The patterns presented in Table 1 are all the more striking since they do not control for per capita income, an important determinant of the success of a country's athletes in international sporting events. In the next section we investigate the effect of LaborRatio on the success of a country's women in the Summer Olympics, controlling for income per capita as well as other factors.

\section{Labor Force Participation and Olympic Success}

The Summer Olympics draws participants from more countries than any other single athletic event. The athletes at the 2000 Sydney Summer Olympics represented 199 countries and territories. Women represented 38 percent of the 10,651 athletes at the Sydney Games. Out of the 290 events at the 2000 Summer Olympics, 118 events (41 percent) were exclusively for women.

The success of a country's women at the Summer Olympics can be explained by a number of factors. The focus this paper is whether this success reflects the relative economic opportunities of women in a country's labor market, as indicated by its value of LaborRatio, and our empirical specifications includes this variable. We also include a variable that measures the success of a country's men in the Olympics. This variable helps to control for a range of unobserved factors that reflect the overall commitment of a country to Olympic sports. As explained in more detail below, this variable takes different forms, depending upon the empirical specification, in order to match it to the particular test for women's success in the Olympics. Finally, all specifications also include two other variables that have been shown in the research cited above to be 
important determinants of the overall success of a country's athletes at the Summer Olympics. The logarithm of a country's population between the ages of 15 and 64 in 1999 (InPop) reflects the size of the initial pool of talent from which elite athletes are drawn. We also include the logarithm of a country's income per capita in 1999 (lnGDPcap) as another regressor since the quality of the pool of potential athletes is a function of the overall physical well-being of the country's population as well as the resources devoted to athletic pursuits, both of which are likely to be positively correlated with income. ${ }^{9}$

Table 2 includes three different sets of tests of the influence of LaborRatio on the success of a country's women at the 2000 Summer Olympics. The first tests (Regressions $1-3$ in Table 2) are probit regressions in which the dependent variable distinguishes between countries whose women won at least one medal and those countries whose women won no medals. In these regressions, the variable AnyMen, representing the success of a country's men at the Olympics, is also dichotomous, taking the value 1 if any men from a country won a medal and otherwise taking the value 0 . The next tests (Regressions $4-6$ in Table 2) are tobit regressions in which the dependent variable is Medals, described above. These regressions include the regressor MedalsMen, representing the number of medals won by a country's men. The final three regressions presented in Table 2 (Regressions 7 -9) also use tobit, but in this case the dependent variable is MedalPts, described above. These regressions include a variable representing the medal points earned by a country's men, MedalPtsMen.

The significance of the control variables, $\ln$ GDPcap, $\ln P o p$, and the variables representing the success of a country's men in the Olympics, on the probability of a

\footnotetext{
${ }^{9}$ A data appendix at the end of the paper discusses the variables used in the analysis.
} 
country's women winning at least one medal, on the number of medals won by a country's women, and on the weighted value of the number of medals won by a country's women is demonstrated in columns 1, 4 and 7, respectively, of Table 2 . In each case, the coefficients on all three of the variables included in the regressions are highly significant, with p-values less than 0.02 for all coefficients.

Our main interest, however, in on the regressions that include LaborRatio. The results presented in columns 2, 5 and 8 augment those in columns 1,4, and 7, respectively, with this variable. In each of these three regressions, the coefficient on LaborRatio is significant, with p-values of about 0.01 or better.

The point estimate of 10.08 in the tobit regression on the number of medals won (Column 5) suggests that women from a country at the $75^{\text {th }}$ percentile of LaborRatio earned 2.82 more medals than their sisters from a country at the $25^{\text {th }}$ percentile solely by virtue of the difference in the relative labor force participation rates (since $2.82=10.08 \mathrm{x}$ $(0.84-0.56))$. This is a notable amount since there were 21 countries whose women won only 1 medal and another 24 whose women won between 2 and 8 . This is also comparable to the ceteris paribus effects of population and income per capita since the differences between the estimated numbers of medals won by women from a country at the $75^{\text {th }}$ percentile and a country at the $25^{\text {th }}$ percentile for these two variables are 2.96 for income per capita and 3.67 for population.

Column 8 of Table 2 present an estimate of the effect of LaborRatio on the medal points earned by women. This estimate suggests that women from a country that has a value of LaborRatio at the $75^{\text {th }}$ percentile value will earn 8.01 more medal points $(28.59 \mathrm{x}$ $(0.84-0.56))$ than women from a country that is otherwise identical but for having a 
value of LaborRatio at the $25^{\text {th }}$ percentile value. The comparable estimates for the differences between the estimated numbers of medal points won by women from a country at the $75^{\text {th }}$ percentile and a country at the $25^{\text {th }}$ percentile of income per capita and population are 7.60 and 10.20 , respectively.

\section{III.A Robustness}

One possible concern with these results is that our measure of the integration of women in the workforce, LaborRatio, is serving as a proxy for other features of a country. For example, we may suspect that those countries that have a higher proportion of women in the labor force may also have a greater presence of women in the government. In this case, it may be that a higher representation of women in government is associated greater support of women's athletics and this, in turn, contributes to the performance of a country's women in the Summer Olympics. In addition, we may suspect that a higher relative labor force participation rate reflects a lower fertility rate, which means that more young women have the opportunity to participate in sports rather than raise children. ${ }^{10}$ This could also contribute to the success of a country's women at the Olympics.

We test for the robustness of LaborRatio to the presence of these variables by augmenting the specification discussed above with two variables, the percentage of women in all levels of a country's government, WomenGov, and the fertility rate of

\footnotetext{
${ }^{10}$ In fact, augmenting the relative labor force participation rate equation presented in Section II with the variables WomenGov and Fertility described in the next paragraph results in the estimated relationship LaborRatio $=2.87-0.50 \ln$ GDPcap $+0.03 \ln$ GDPcap ${ }^{2}+0.004$ WomenGov -0.04 Fertility This regression is run on data from 146 countries and the $\mathrm{R}^{2}$ is 0.22 . All the coefficients in this equation are significant at better than the 95 percent level of confidence.
} 
women in a country, Fertility. ${ }^{11}$ These results are reported in Columns 3, 6 and 9 of Table 2. In each case, the coefficient on LaborRatio is smaller when WomenGov and Fertility are included in the regression, confirming, to some extent, our concern.

However, the p-values on the coefficient on LaborRatio are 0.035, 0.027 and 0.08 in the regressions in columns 3, 6, and 9, respectively, showing that LaborRatio has a significant effect on the probability of a country's women winning at least one medal, on the number of medals won by a country's women, and on the weighted value of the number of medals won by a country's women, even when including these two variables.

We also conducted robustness tests by including three different dummy variables; one denoting countries that were members of the former Soviet Union, one denoting other countries in Eastern Europe, and one denoting the host country, Australia. ${ }^{12}$ In a tobit regression of the number of medals won by a country's women that includes these three dummy variables, as well as those included in the specification in Column 6 of Table 2, the coefficient on LaborRatio is 8.32 (which is larger than the value of the coefficient reported in Column 6) and its p-value is 0.017 . This increase in the value of the coefficient on LaborRatio with the inclusion of these three regional dummy variables also occurs in a tobit regression in which the dependent variable is MedalPts. In this case, augmenting the specification reported in Column 9 with the three regional dummy variables results in an estimated coefficient on LaborRatio of 21.82, with a p-value of

\footnotetext{
${ }^{11}$ The effect of LaborRatio on the probability of a country's women winning any medals, on the number of medals won by a country's women, or on the number of medal points earned by a country's women is virtually the same whether we use WomenGov or, alternatively, the percentage of women in ministerial level positions or the percentage of women in sub-ministerial positions, two other variables available in the Human Development Report.

${ }^{12}$ Grimes, Kelly and Rubin (1974), Bernard and Busse (2000), Johnson and Ali (2000), and Kuper and Sterken (2001a) control membership in the former Soviet bloc and whether a country is hosting the games.
} 
0.058. A probit regression like the one presented in Column 3 that drops Australia and also includes two dummy variables, one for Eastern European countries and another for countries that were former members of the Soviet Union, yields a point estimate of 2.57 for the coefficient on LaborRatio, with a p-value of 0.03 .

\section{III.B Individual Events versus Team Events}

We close this section with an investigation of whether the effect of LaborRatio on the number of medals won by women differs across team and individual events. There were 260 medals awarded for individual events to women from the 149 countries included in our data set, and 100 medals awarded to teams that included women. Table 3 presents tobit regressions in which the dependent variable is either the number of medals won by women in individual events (in Columns 1 and 2) or the number of medals won by teams that included women (in Columns 3 and 4). Thus, these regressions take the form of those presented in Columns 5 and 6 of Table 2.

The results presented in Table 3 suggest that there is a slightly larger effect of LaborRatio on the number of medals won by women in individual events than on the number of medals won by women in team events, but this difference is not statistically significant. The coefficient on LaborRatio is significant at better than the 97 percent level in the regressions reported in Columns 1, 2 and 3. Only the results in Column 4 fail to present a significant coefficient for LaborRatio. But in this regression, the F-test of the joint significance of the coefficients on LaborRatio and Fertility has a p-value of 0.03, while the p-values for the individual coefficients are 0.12 and 0.09 , respectively.

In addition, we also used a dummy variable that indicated whether a country was predominantly Muslim and found that this was insiginificant and its inclusion did not alter the estimated effect of LaborRatio. 
We next turn to an analysis of relative labor force participation rates on the outcome of an event that includes only team competition, the Women's Soccer World Cup.

\section{Labor Force Participation and the Women's World Cup}

Like many other team sports, recent years have seen an increase in women's participation in soccer. One reflection of this was the institution of the Women's World Cup in 1992. In the run-up to the third Women's World Cup, which was held in the United States in 1999, national teams from 59 countries and territories competed for the fifteen available slots in the competition. ${ }^{13}$

In this section we demonstrate that the relative labor force participation rate is a significant determinant of both the likelihood of a women's national soccer team qualifying for one of the available slots in the Women's World Cup competition in 1999 and the performance of those 16 teams that participated in the World Cup. This effect holds while controlling for factors similar to those that determine the success of a country's women in the Olympics, including population and income per capita. In addition, we may think that some countries are more devoted to soccer than others, so we also include as a regressor a dummy variable indicating whether a country's men's soccer team qualified for the 1998 World Cup (Cup98Men).

The first four columns of Table 4 present probit estimates of the likelihood of a country's team qualifying for the 1999 Women's World Cup. The countries included in the analysis include those that competed for a slot in the World Cup and for which we

\footnotetext{
${ }^{13}$ The United States, as host country, was automatic ally awarded one slot.
} 
have complete data. The United States, which automatically qualified for a slot, is not included in these estimates. The estimates in Columns 1, 2 and 4 do not include North Korea, a country that did qualify for the 1999 Women's World Cup, since there is no available data on its income per capita. To check for the possible influence of North Korea on the results, Column 3 presents a specification without income per capita which does include an observation for North Korea. ${ }^{14}$

The estimate presented in Column 1 includes the control variables $\operatorname{lnGDPcap}$, InPop, and Cup98Men. The p-values of the coefficient on InPop and InGDPcap are 0.004 and 0.099, respectively, while the coefficient on Cup98Men is not significant. The estimate presented in Column 2 introduces LaborRatio, and the coefficient on this variable is a significant at better than the 99 percent level of confidence. The pseudo- $\mathrm{R}^{2}$ of the regression rises from 0.21 to 0.37 with the inclusion of LaborRatio. Furthermore, the inclusion of LaborRatio makes the coefficient on InGDPcap insignificant. We drop InGDPcap from the specification in the estimate reported in Column 3, which allows us to include North Korea as an observation. In this case, the coefficient on LaborRatio has a p-value of 0.001 . The results presented in Column 4 show that the significant effect of LaborRatio on the probability of a country's team qualifying for the World Cup is robust to the inclusion of WomenGov and Fertility in the regression, with a p-value of the coefficient on LaborRatio equal to 0.009 in this case.

Columns 5 through 8 of Table 4 presents tobit estimates in which the dependent variables is Cup99Points (which represents $1+$ the number of points earned in World

\footnotetext{
${ }^{14} \mathrm{Six}$ other countries and territories that competed in tournaments to qualify could not be included because of a lack of data on population. These include Guam, Taiwan, Martinique, Puerto Rico, Tonga, and Western Samoa. Hong Kong does not have data on the percentage of women in government, so it is not included in the regressions in Columns 4 and 8 of Table 4.
} 
Cup Competition, as discussed in Section II). ${ }^{15}$ LaborRatio is a significant determinant of this variable, as shown in the results in Columns 6 through 8 , with p-values of less than 0.01 in all three cases. The inclusion of LaborRatio raises the pseudo- $\mathrm{R}^{2}$ from 0.12 (as shown by the results in Column 5) to $0.21 .^{16}$

The effect of LaborRatio on the number of points earned in World Cup competition is also evident when we restrict the sample to the 16 teams that qualified for the event in 1999. We regress the number of points won by a team that participated in the World Cup (i.e. Cup99Points - 1) against LaborRatio, Cup98Men and lnPop, dropping lnGDPcap and WomenGov as regressors since data on these variables are not available for North Korea. The estimated relationship is

$$
\begin{aligned}
& (\text { Cup99Points }-1)=\mathbf{- 8 1 . 8 6}+\mathbf{3 4 . 7 6} \text { LaborRatio }+7.60 \text { Cup98Men }+\mathbf{3 . 3 5} \text { lnPop } \\
& \text { (22.21) (13.92) (4.26) }
\end{aligned}
$$

where robust standard errors appear in parentheses below the coefficient values, bold represents a coefficient significant at better than the 95 percent level of confidence, and italic represents a coefficient significant at between the 90 percent and 95 percent levels of confidence. The $\mathrm{R}^{2}$ of this regression is 0.50 . Figure 3 presents a visual depiction of

\footnotetext{
${ }^{15}$ Adding 1 to the number of points earned in World Cup competition enables us to distinguish between Mexico and Denmark, two countries whose teams qualified for the World Cup but lost all their games, and other countries whose teams did not qualify for the World Cup.

${ }^{16}$ As a robustness check of both the probit and tobit estimates, we augmented the specifications that include WomenGov and Fertility with two dummy variables, one representing countries that were members of the former Soviet Union and one representing countries that are predominantly Muslim. The coefficient on LaborRatio is 6.67 and its p-value is 0.014 in a probit regression that includes these two dummy variables as well as the other variables included in the specification reported in Column 4. A tobit regression that includes these two dummy variables as well as the others included in the specification of Column 8 has a coefficient on LaborRatio of 45.93 with a p-value below is 0.001 . In neither case are the dummy variables significant.
} 
the ceteris paribus effect of LaborRatio on the number of points earned in the 1999 Women's World Cup with a partial regression leverage plot of this relationship. ${ }^{17}$

The pattern of significance of the other variables included in Table 4 bears mention. There is a significant effect of Cup98Men in the tobit regressions, with p-values of $0.07,0.02$ and 0.02 in the estimates reported in Columns 6, 7, and 8, respectively. The importance of this variable is less pronounced in the probit regressions. Population is a significant determinant of the number of points earned by teams in World Cup competition in all specifications reported in Table 4. The coefficient on WomenGov is significant at the 93 percent level of confidence in the regression reported in Column 4, and at better than the 99 percent level of confidence in the regression reported in Column 8. Neither the estimates in Column 4 nor those in Column 8 include a significant effect of Fertility. Interestingly, the estimate in Column 4 of Table 3 also did not indicate that Fertility is a significant determinant of the number of medals won by teams in the Summer Olympics, although there is a significant effect of this variable on the number of individual medals. Perhaps this is linked to the fact that the average age of women in individual sports, like swimming or gymnastics, is lower than the average age of women in team sports.

\footnotetext{
${ }^{17}$ These countries (and their three-letter codes used in Figure 3) included Australia (AUS), Brazil (BRA), Canada (CAN), China (CHN), Denmark (DNK), Germany (DEU), Ghana (GHA), Italy (ITA), Japan (JPN), North Korea (PRK), Mexico (MEX), Nigeria (NGA), Norway (NOR), the Russian Federation (RUS), Sweden (SWE), and the United States (USA).
} 


\section{$\underline{\text { V. Conclusion }}$}

This paper demonstrates a link between an economic and social feature of countries, the relative labor force participation rate of women, and a high-profile characteristic, the performance of women in international sports competitions. Countries in which women participate more fully in the labor force tend to be ones whose women performed better in the Sydney Summer Olympics in 2000, and whose women's teams both were more likely to qualify for the 1999 Women's World Cup and performed better in this event. This effect holds when controlling for factors shown, in other research, to determine national Olympic success, like income per capita and population. In addition to these variables, we also control for the athletic success of a country's men, the rate of participation of women in government and the fertility rate.

These demonstrated statistical relationships, between relative labor force participation and athletic success, are silent as to causes. It is reasonable to conjecture, however, that societies in which women have greatere economic opportunities are ones that enable athletically talented women to reach their full potential. In these societies, women are more likely to be able to succeed in both work and play. 


\section{Bibliography}

Ball, Donald.W., "Olympic Games Competition: Structural Correlates of National Success," International Journal of Comparative Sociology, 1972, vol. 15, pp. $186-200$.

Bernard, Andrew B. and Meghan R. Busse, "Who Wins the Olympic Games: Economic Development and Medal Totals," N.B.E.R. Working Papers number 7998, November 2000.

Grimes, A.Ray, William.J. Kelly and Paul.H. Rubin, “A Socioeconomic Model of National Olympic Performance," Social Science Quarterly, 1974, vol. 55, pp. $777-782$.

International Bank for Reconstruction and Development, World Development Indicators 2001.

Johnson, Daniel K.N. and Ayfer Ali, "Coming to Play or Coming to Win: Participation and Success at the Olympic Games," Wellesley College Working Paper 2000-10, September 2000.

, "A Tale of Two Seasons: Participation and Medal Counts at the Summer and Winter Olympic Games," Wellesley College Working Paper 2002-02, January 2002.

Kuper, Gerard and Elmer Sterken, "Olympic Participation and performance since 1896," mimeo, Department of Economics, University of Groningen, 2001a.

, "The Olympic Winter Games: Participation and performance," mimeo, Department of Economics, University of Groningen, 2001b.

Levine, Ned, "Why Do Countries Win Olympic Medals? Some Structural Correlates of Olympic Games Success: 1972," Sociology and Social Research, 1974, vol. 58, pp. $353-360$.

Mammen, Kristin and Christina Paxson, "Women's Work and Economic Development," Journal of Economic Perspectives, Fall 2000, volume 14, number 4, pp. $141-164$. 


\section{Data Appendix}

Olympic Medals: CBS SportsLine.com. See www.cbs.sportsline.com/u/olympics/2000/medaltracker/medalcount.htm and http://www.slam.ca/2000GamesMedals/home.html

World Cup Performance: Women's Soccer World Online. See www.womensoccer.com/wwcup99/wwcresults/wwcscores.html

Fertility Rates: From World Development Indicators 2001 CD-ROM.

GDP per capita: 1999 values, at PPP rates, in 1999 dollars values, from World Development Indicators 2001 CD-ROM.

Population Aged 15 - 64: In 1999, from World Development Indicators 2001 CD-ROM.

LaborRatio: 1999 values, Female labor force activity rate (measured as \% of female population ages 15-64) divided by Male labor force activity rate (measured as $\%$ of male population ages 15-64), from World Development Indicators 2001 CD-ROM. Values for 1979, 1989 and 1994, mentioned in footnote 5, are also obtained from this source.

Women in Government: Percentage of women in government at all levels, including elected heads of state and governors of central banks. 1996 value. From Human Development Report 1999 CD-ROM. 


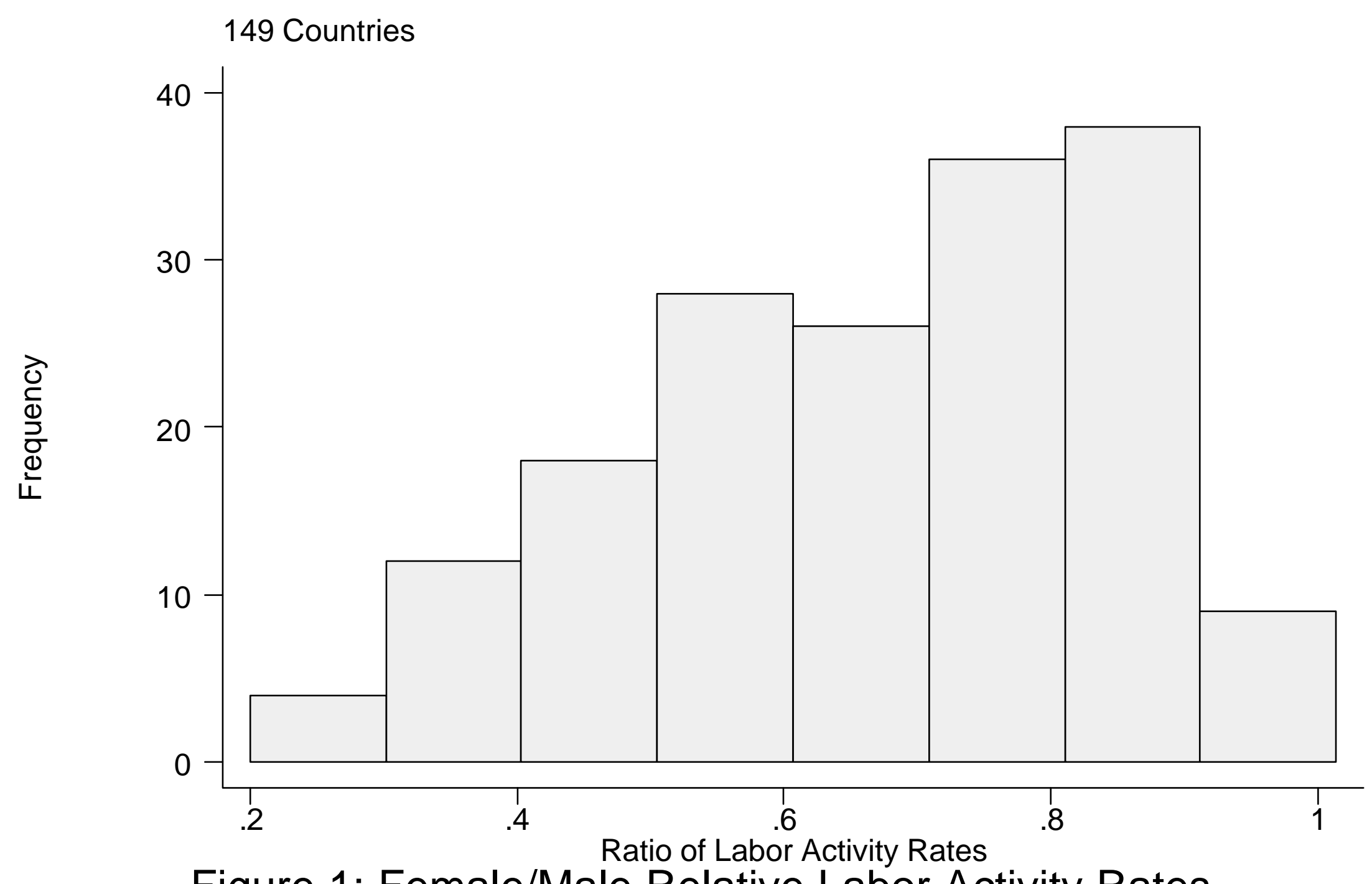

Figure 1: Female/Male Relative Labor Activity Rates 


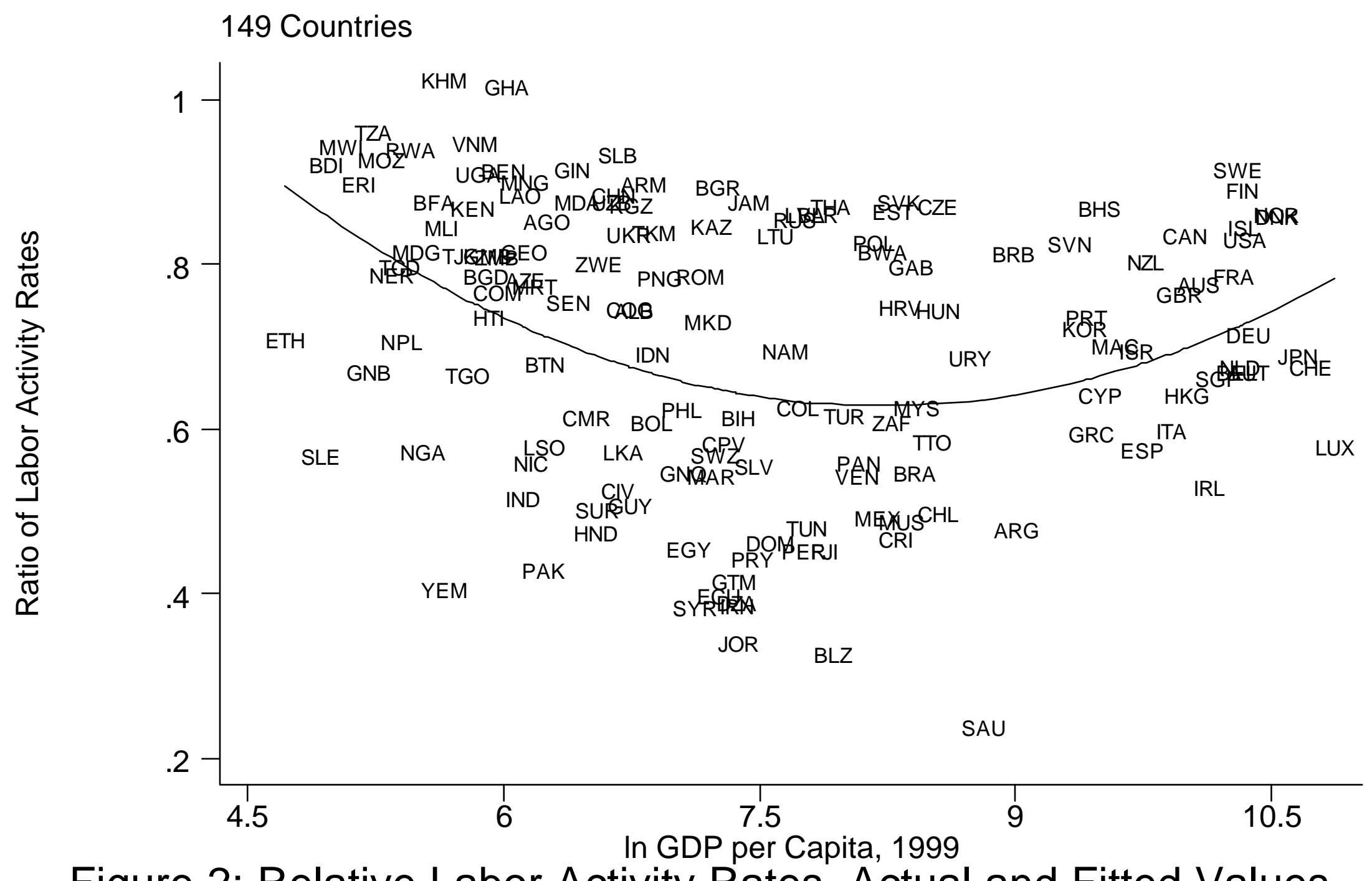

Figure 2: Relative Labor Activity Rates, Actual and Fitted Values 


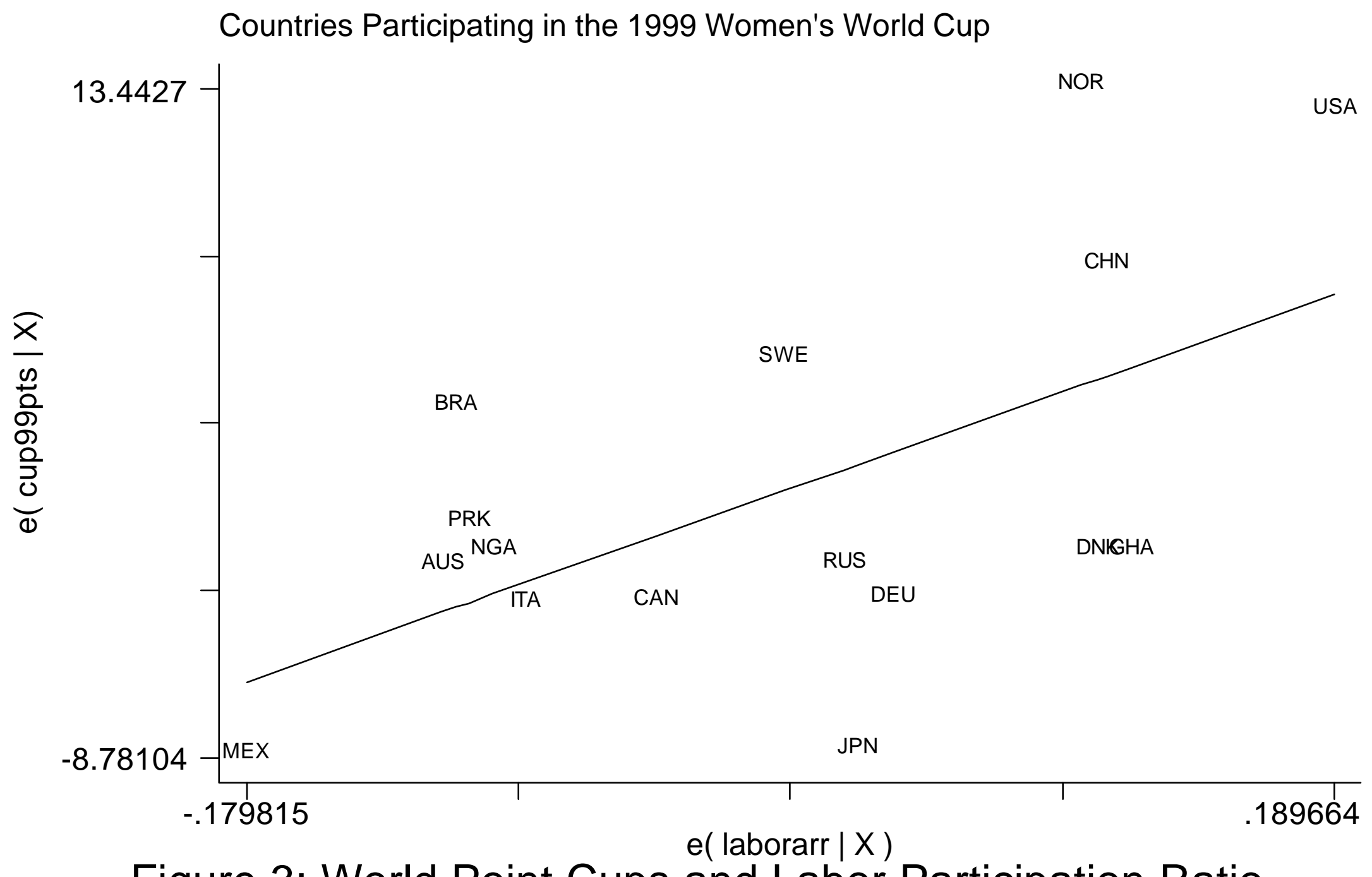

Figure 3: World Point Cups and Labor Participation Ratio 


\begin{tabular}{|c|c|c|c|c|c|}
\hline \multicolumn{6}{|c|}{ Table 1: Labor Ratio Quartiles and Women's Athletic Performance Measures } \\
\hline \multicolumn{3}{|c|}{2000 Sydney Summer Olympics } & \multicolumn{3}{|c|}{1999 Women's World Cup } \\
\hline Quartile (n=149) & Medals & MedalPoints & Quartile $(n=53)$ & Cup99 & Cup99Points \\
\hline I $(0.22<$ LaborRatio $<0.56)$ & 14 & 28 & I $(0.38<$ LaborRatio $<0.54)$ & 2 & 15 \\
\hline II $(0.56<$ LaborRatio $\leq 0.73)$ & 99 & 279 & II $(0.54<$ LaborRatio $\leq 0.67)$ & 2 & 13 \\
\hline III $(0.73<$ LaborRatio $\leq 0.84)$ & 138 & 404 & III $(0.67<$ LaborRatio $\leq 0.82)$ & 5 & 39 \\
\hline IV $(0.84<$ LaborRatio $\leq 1.01)$ & 109 & 357 & IV $(0.82<$ LaborRatio $\leq 1.01)$ & 7 & 57 \\
\hline
\end{tabular}




\begin{tabular}{|c|c|c|c|c|c|c|c|c|c|c|c|c|c|c|c|}
\hline \multicolumn{10}{|c|}{ Table 2: Women's Olympic Performance } \\
\hline
\end{tabular}

\section{Definition of Variables:}

LaborRatio - Female labor force activity rate (measured as \% of female population ages 15-64) divided by Male labor force activity rate (measured as \% of male population ages 15-64), 1999 value.

InGDPcap - GDP per capita in 1999, at PPP rates, in 1999 US dollars.

lnPop - Population Aged 15 - 64 in 1999.

WomenGov - Percentage of women in government at all levels, including elected heads of state and governors of central banks, in 1996.

Fertility - Fertility rate.

AnyMen - 1 if any medals won by men from a country, else 0 .

MedalsMen - Number of medals won by men from a country.

MedalPtsMen - Number of medal points (gold=5, silver=3, bronze=1) won by men from a country. 


\begin{tabular}{|c|c|c|c|c|c|c|c|c|}
\hline \multicolumn{9}{|c|}{ Table 3: Women's Olympic Individual Medals and Team Medals } \\
\hline & \multicolumn{4}{|c|}{$\begin{array}{l}\text { Number of Medals Won by Women in } \\
\text { Individual Events: Tobit Analysis }\end{array}$} & \multicolumn{4}{|c|}{$\begin{array}{c}\text { Number of Medals Won by Women's } \\
\text { Teams: Tobit Analysis }\end{array}$} \\
\hline Regression No. & \multicolumn{2}{|c|}{1} & \multicolumn{2}{|c|}{2} & \multicolumn{2}{|c|}{3} & \multicolumn{2}{|c|}{4} \\
\hline Variable & $\hat{a}$ & s.e. & $\hat{a}$ & s.e. & $\hat{a}$ & s.e. & $\hat{a}$ & s.e. \\
\hline LaborRatio & 7.88 & 2.59 & 6.11 & 2.66 & 7.11 & 2.97 & 5.10 & 3.28 \\
\hline $\operatorname{lnGDPcap}$ & 0.97 & 0.26 & 0.30 & 0.34 & 0.95 & 0.27 & 0.52 & 0.34 \\
\hline $\operatorname{lnPop}$ & 1.56 & 0.30 & 1.51 & 0.31 & 0.74 & 0.28 & 0.76 & 0.30 \\
\hline MedalsMen & 0.37 & 0.04 & 0.36 & 0.04 & 0.21 & 0.04 & 0.20 & 0.04 \\
\hline WomenGov & & & 0.05 & 0.05 & & & 0.04 & 0.05 \\
\hline Fertility & & & -1.04 & 0.39 & & & -1.08 & 0.64 \\
\hline Pseudo $\mathrm{R}^{2}$ & \multicolumn{2}{|c|}{0.32} & \multicolumn{2}{|c|}{0.33} & \multicolumn{2}{|c|}{0.39} & \multicolumn{2}{|c|}{$\frac{1}{0.40}$} \\
\hline No. of obs. & \multicolumn{2}{|c|}{149} & \multicolumn{2}{|c|}{146} & \multirow{2}{*}{\multicolumn{2}{|c|}{149}} & \multicolumn{2}{|c|}{146} \\
\hline \multicolumn{7}{|c|}{ Bold $=$ Significant at $95 \%$ level ; talic $=$ Significant at $90 \%$ level } & & \\
\hline
\end{tabular}




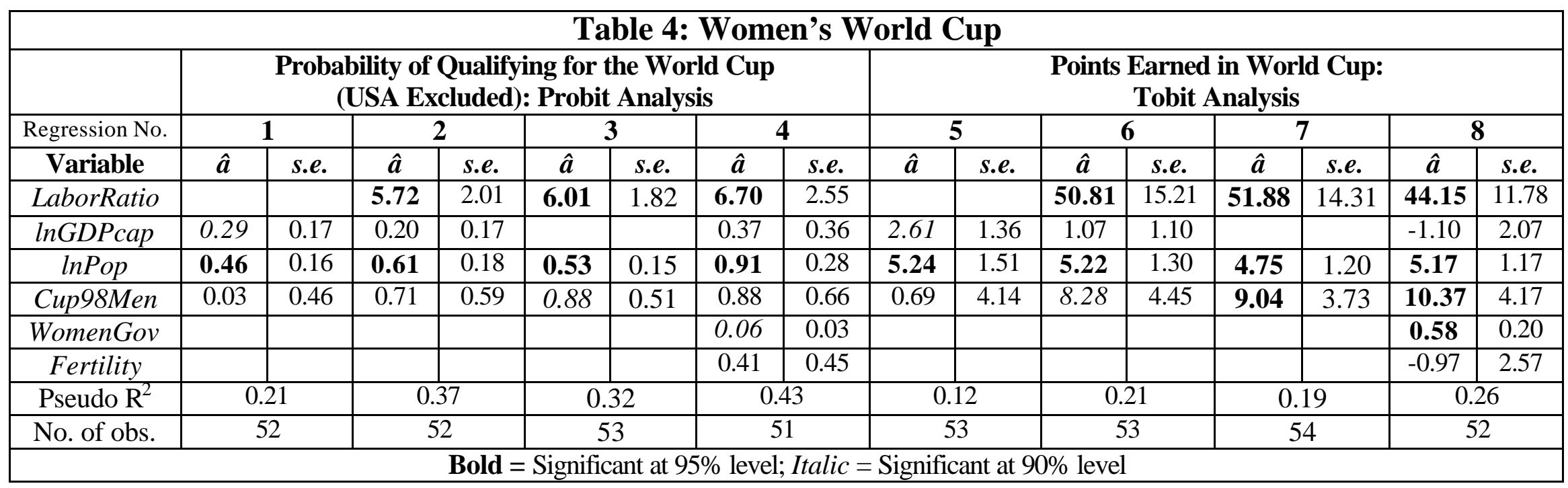

